\title{
Use of the gas ionization signal for combustion process diagnostics in the cylinder of a spark ignition engine
}

\begin{abstract}
The running diagnostics of the combustion process in an internal combustion engine is essential for increasing its efficiency and to improving its performance indicators. The modern diagnostics of this process no longer concerns only measurements of fast-changing thermodynamic variables, but also measurements of other parameters allowing for its evaluation. The use of electrical or optical methods in diagnostics enables the evaluation of local process parameters, such as occurrence of the flame and its temperature distribution. Actually, there are some new methods under investigation which are proposed for this kind of diagnostic.

This article focuses on demonstrating the potential for using an electric signal from the gas ionization to estimate the maximum combustion pressure in a cylinder of an SI engine. This is a comparative analysis of the gas ionization current signal in the cylinder and the fast-changing pressure at fixed operating points of a 4-stroke natural gas powered engine. The study was carried out on a one-cylinder 4-stroke SI engine equipped with a cylinder pressure recording system and monitoring of the cylinder ionization current using appropriate measuring systems. The influence of engine operating conditions on the ability to determine cylinder pressure based on the ionization current signal was analyzed. This impact assessment was analyzed statistically and a strong correlation was found between the analyzed signals. The obtained results point in the potential direction of development of this type of measuring system.
\end{abstract}

Key words: gas engine, ionization sensor, pressure sensor, engine control, lean fuel mixture

\section{Introduction}

Modern fast-changing pressure sensors used in diesel engine diagnostics allow high-frequency combustion pressure measurement under extreme operating conditions at high temperatures and in-cylinder pressures. The pressure profile inside the combustion chamber may be an important component of the procedure used to control the internal combustion engine, allowing continuous thermodynamic analysis of the process in real time and thereby enabling improved energy conversion efficiency and reduction of harmful substance emissions.

Due to the relatively high cost of manufacturing piezoelectric sensors, their usefulness is limited only to laboratory tests or to more expensive units used in motor vehicles. However, there are signs that optical methods of evaluating thermodynamic indicators and measuring the gas ionization degree may be a viable alternative. Optical methods rely on the analysis of light waves, but they require alterations in the engine design and the use of appropriate measured signal processing equipment [1]. Measurement of the so-called ionization current, i.e. the current flowing through the medium after ignition, enables the use of a standard spark plug in spark ignition engines, significantly reducing the cost of using a measuring system [2].

The ionization current signal has already been used for many motor applications. Byttner and Holmberg [3], by analyzing the ionizing current signal, showed a large effect of the recirculated exhaust gas on its amplitude and its nature while proving the possibility of using such a signal as a EGR content percentage sensor in the medium. With exhaust gas recirculation, combustion is slower and the temperature is lowered, resulting in smaller, time-shifted amplitude.

The ionization signal allows to determine the time when the maximum pressure in the combustion chamber is reached - this feature was used by Eriksson et al. [4] and Hellring et al. [9] when designing ignition feedback systems that control the position of the maximum combustion pressure point.

Mehresh et al. [5] analyzed the use of the HCCI spark plug as an ionization sensor, an alternative to expensive pressure transducers. The ionization current was measured when the engine was running on a lean fuel mixture. A small amount of the so-called chemical ionization has been found due to low-temperature combustion processes in this type of an engine.

Successful ionization current measurement can also be used in compression ignition engines, but most often it involves significant modifications to the engine [6].

The very high dependence of the ionization signal on the excess air ratio was demonstrated by Filipek et al. [2] and Abhijit et al. [7]. They have been able to control the fuel injection using an ionization signal. They further noticed that the ionization sensor showed a much faster response to changes in the fuel composition from the commonly used oxygen sensor, but unfortunately, its signal is highly unrepeatable.

The most common use of the ionizing current signal is knock detection and ignition detection [8, 10, 11]. Prominent manufacturers (Mazda, Harley-Davidson) use this type of system as a standard. The ionization current is used in a very limited range, but its efficiency and response time are incomparably shorter than conventional sensors, and the use of such a sensor significantly reduces costs by reducing the number of components required.

\section{Ionization signal characteristics}

In a short time after the discharge on the electrodes of the spark plug an intensive propagation of the flame in the mixture takes place - from the spark plug towards the cylinder walls, this is due to the intense chemical reactions 
sustaining the combustion process. As a result of these reactions, free ions and electrons are produced in the socalled chemical ionization process. The stage of thermal ionization is associated with the formation of ions and electrons due to the effects of temperature and pressure.

Measurement of the degree of ionization in the combustion chamber - for the purposes of this article - was carried out using the system shown in Figure 1. At the time when the electric arc disappears, a constant voltage of about 80 volts was applied to the spark plug electrodes. The presence of free ions and electrons in the burning gas, causes a small current in the circuit (ionization current) of the order of several dozen microamps. According to Ohm's Law, a potential difference (ionization voltage) measured directly in the circuit is generated on the resistor connected to the circuit.

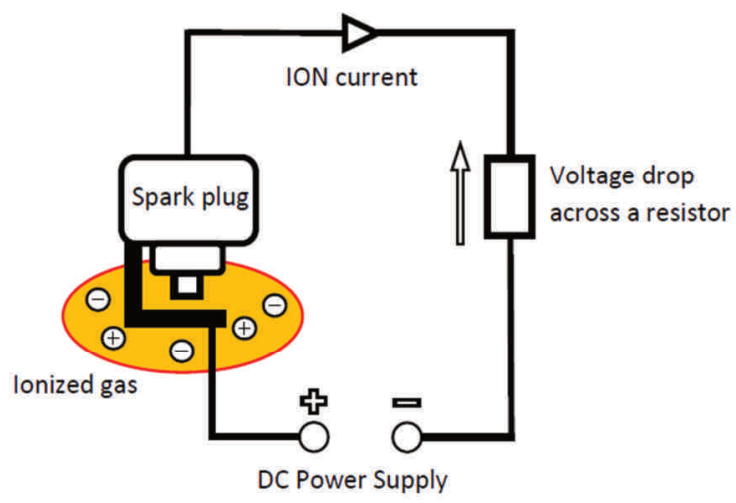

Fig. 1. Diagram of the ionization signal measurement circuit

Figure 2 shows an example of ionization voltage signal measurement along with the identified process steps [4, 7]. There are three main phases in this process:

a) ignition phase I - strong electromagnetic radiation from the ignition system - it causes interference in the ionization signal, making it difficult to analyze,

b) chemical ionization phase II - strongly associated with the formation of the flame front,

c) thermal ionization phase III - has a high correlation with maximum cylinder pressure and temperature.

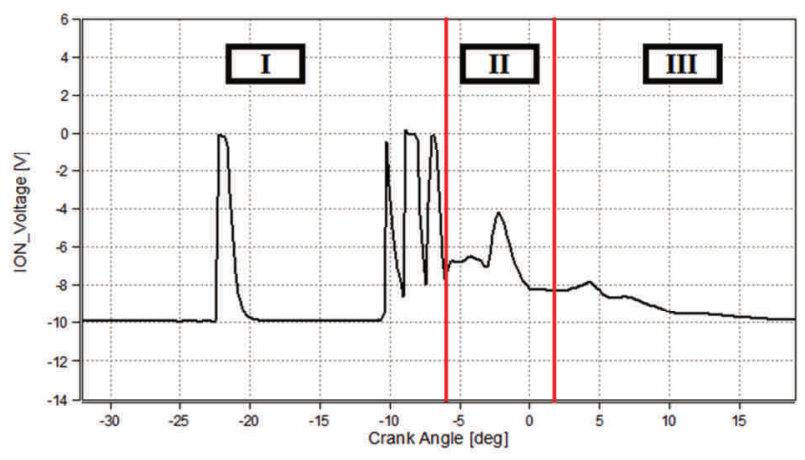

Fig. 2. Ionization voltage signal with defined phases

\section{Motivation}

Ionization current signal applications - presented in Chapter 1, mainly refer to engines powered using a stoichiometric gasoline mixture. There is little information in the literature on the use of this signal when burning gas mixtures.

The aim of this article is to try and determine the potential utilization of a diagnostic signal, such as the ionization voltage, for the combustion process diagnostics of an SI combustion engine powered by natural gas. Because of the strong association of the thermal ionization signal to the combustion pressure and the electromagnetic interference that limits the analysis of the chemical ionization signal, the authors focused on the third phase of the ionization signal the thermal ionization.

Analysis of the results of such studies will allow to supplement information on the potential applications of the ionization voltage signal in the combustion of gaseous fuels in enclosed chambers.

\section{Methodology}

\subsection{Test engine}

The study was conducted on a one-cylinder, four-stroke AVL 5804 spark ignition engine. The basic compression ignition engine unit was adapted for the use of natural gas (Table 1). The compression ratio was reduced and the drive system was modified. An indirect injection of natural gas was applied to the intake manifold. The choice of fuel has provided a quite wide ignition range and the use of rich and lean fuel blends to increase the versatility of the results.

Table 1. Characteristics of the research engine

\begin{tabular}{|l|c|c|}
\hline Parameter & Unit & Value \\
\hline Engine & - & 1-cylinder, 4-valve, SI \\
\hline Cylinder volume & $\mathrm{dm}^{3}$ & 0.5107 \\
\hline Bore x stroke & $\mathrm{mm}$ & $85 \times 90$ \\
\hline Compression ratio & - & 15.5 \\
\hline Fuel system & - & $\begin{array}{c}\text { Indirect gas-injection } \\
\text { (electromagnetic injector) }\end{array}$ \\
\hline Air system & - & Supercharging \\
\hline
\end{tabular}

\subsection{Research station}

Ionization currents were measured at a constant engine speed of $1500 \mathrm{rpm}$. To maintain constant thermodynamic conditions, the station is equipped with a liquid and oil conditioning system. The natural gas supply system contained a high pressure tank with a reducer, a Bronkhorst 111B flow meter, and an additional volume of $2 \mathrm{dm}^{3}$ to reduce the wave phenomena present in the system (Fig.3, Table 2). The Bosch gas injector was placed in a spiral inlet duct.

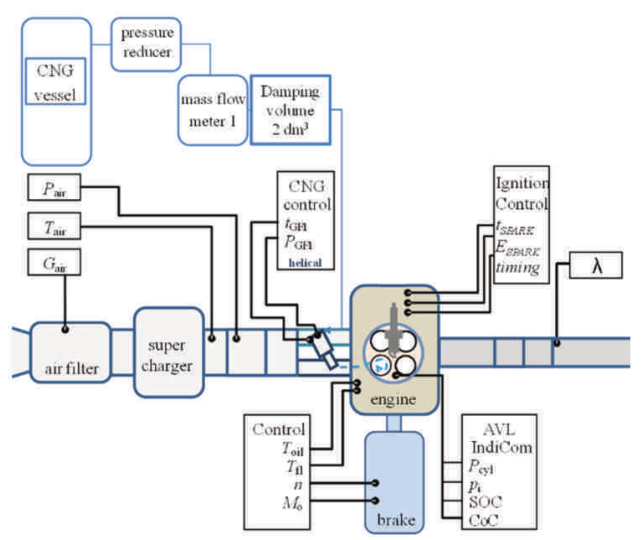

Fig. 3. Test rig for natural gas supply through indirect injection 
Table 2. Measuring apparatus used in the tests

\begin{tabular}{|l|l|c|}
\hline Parameter & Producer/name & Description \\
\hline Engine brake & AVL AMK DW13-170 & $-50-300 \mathrm{Nm}$ \\
\hline Air system & Sensycon Sensyflow & $0-720 \mathrm{~kg} / \mathrm{h}$ \\
\hline Fuel system & Bronkhorst 111B & $0.1-100 \mathrm{~g} / \mathrm{h}$ \\
\hline Oil system & AVL 577 & $0-150 \mathrm{deg} \mathrm{C}$ \\
\hline $\begin{array}{l}\text { Water sys- } \\
\text { tem }\end{array}$ & AVL 577 & $0-150 \mathrm{deg} \mathrm{C}$ \\
\hline $\begin{array}{l}\text { Fast-varying } \\
\text { processes }\end{array}$ & AVL IndiSmart & $\begin{array}{c}\text { 8-channel acquisition } \\
( \pm 10 \mathrm{~V})\end{array}$ \\
\cline { 2 - 3 } & AVL Concerto & Post-processing \\
\hline $\begin{array}{l}\text { Lambda } \\
\text { sensor }\end{array}$ & Bosch LSU 4.9 & $\lambda>0.5$ \\
\hline
\end{tabular}

In order to ensure high combustion pressures, the engine was supercharged with an external engine boost system. The air mass supplied to the cylinder was determined on the basis of the air flow meter. The gas dose - with adjustable timing and angle of injection - was delivered to the injector at a pressure of 9 bar. The ignition controller (from Mechatronics Comp./Poznan) enabled setting the ignition angle and the discharge energy value determined by the coil charging time. In order to control the quality of the air-fuel mixture supplied to the cylinder, a Bosch LSU 4.9 wideband probe was installed at the exhaust outlet. Measurement signals were sent to the AVL IndiSmart Data Acquisition System, which is compatible with AVL Concerto software, enabling real-time analysis of data.

\subsection{Scope of the research}

The scope of the research was based on the motivation to undertake the research problem presented in Chapter 3. The authors wanted to demonstrate that:

1) there is a dependence of the ionization current signal amplitude on the maximum cylinder pressure (Pmax),

2 ) it is possible to associate the angle of the maximum thermal ionization signal value occurring and the angle of the maximum cylinder pressure ( $\alpha \_P$ max).

The desire to demonstrate the above relationships has forced the use of certain engine settings. They were adopted as reference conditions and are presented in Table 3.

Table 3. Reference conditions for conducted research

\begin{tabular}{|l|c|}
\hline \multicolumn{2}{|c|}{ Reference parameters } \\
\hline Engine speed & $1500 \mathrm{rpm}$ \\
\hline Oil/coolant temperature & $80^{\circ} \mathrm{C}$ \\
\hline Maximum pressure & $66-98 \mathrm{bar}$ \\
\hline Angle of Pmax & $0-10 \mathrm{deg}$ \\
\hline$\lambda$ & 1.0 \\
\hline Coil current & $3 \mathrm{~A}$ \\
\hline
\end{tabular}

\section{Influence of maximum cylinder pressure on the thermal ionization voltage value}

Determining the dependence of the ionization voltage on the maximum combustion pressure required a constant value of the maximum pressure angle ( $\alpha \_$Pmax) in order to eliminate the additional disturbance factor (that the change in this angle would be). This value was set at 5 degrees after TDC at constant charging coil current value $-3 \mathrm{~A}$ and constant excess air ratio $-\lambda=1$. The increase in maximum combustion pressure was achieved in part through adjusting the air supply by increasing the throttle opening angle as well as increasing the supercharging gas pressure along with an increase in the fuel dose (adjusted with $\lambda=$ const). Achieving the required operating points required adjusting the ignition angle using a dedicated controller. In-cylinder pressure and ionization voltages were averaged (out of 100 measurement cycles) and then analyzed further (Fig. 4).

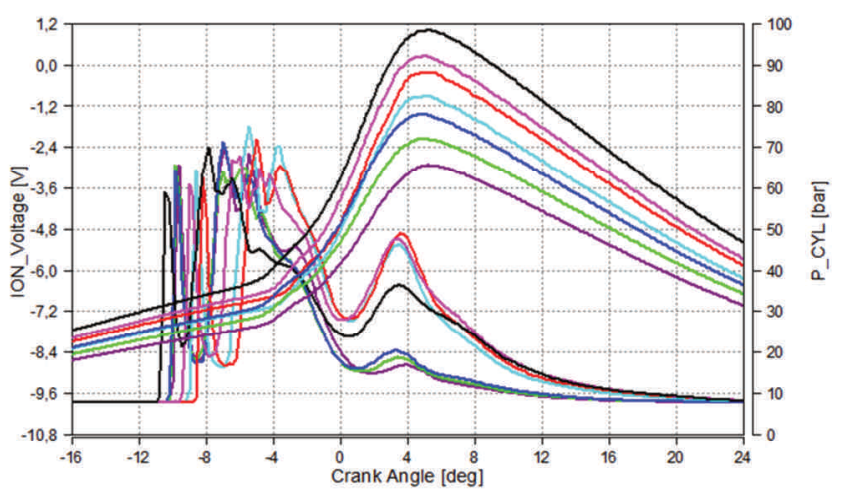

Fig. 4. Effect of the maximum combustion pressure on the thermal ionization signal value

As a result of the high non-repetitiveness and variation of the recorded signal (Figure 4), the chemical ionization phase was averaged together with the first ignition phase part, which made it impossible to analyze further. The thermal ionization voltage was then used to analyze the relationship between this signal and the maximum cylinder pressure. The results of this research test are shown in Figure 5.

The relation shown here is a partial correlation of maximum combustion pressure and ionization voltage (within one setpoint of supercharging pressure). The first three points were recorded by adjusting the throttle opening, while the remaining points by increasing the supercharge pressure and adjusting the throttle opening angle. It is probably the pressure increase in the intake system, and thus the increase in the temperature of the supercharged air, that affects the thermal ionization voltage value.

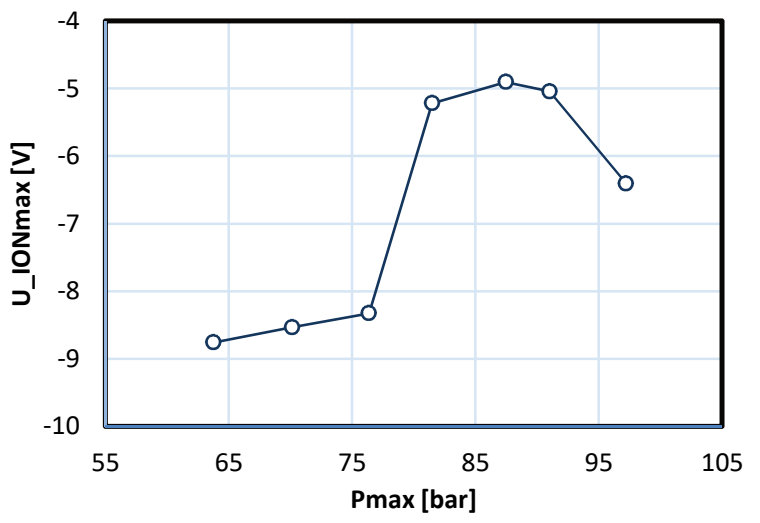

Fig. 5. Graph of the relation between maximum combustion pressure and ionization voltage value

\section{Effect of the maximum combustion pressure angle on the thermal ionization voltage signal}

In order to relation between the maximum combustion pressure angle and the ionizing current signal, changes in the maximum combustion pressure angle in the range of 0 - 
10 degrees on the crankshaft after TDC were recorded. These adjustments were made by changing the ignition advance angle setting in the range of 6-19 degrees on the crankshaft before TCD. Other parameters, such as air excess ratio $(\lambda)$ and coil charging current were assumed as reference values. The results were averaged and further analyzed (Figure 6).

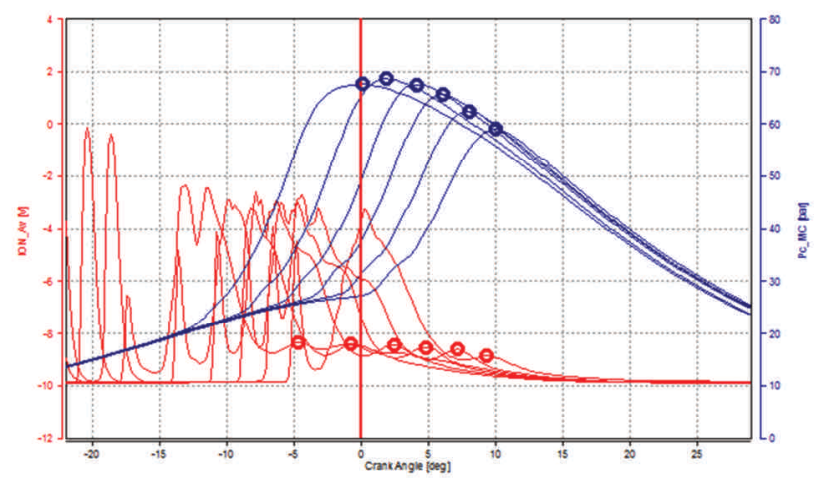

Fig. 6. The effect of the maximum combustion pressure angle (blue line) on the thermal ionization signal (red line)

For analysis aiming to determine the relationship between the maximum cylinder pressure angle and the ionization signal, thermal ionization values were used. The dependence of the angle of the maximum combustion pressure ( $\alpha \_$Pmax) on the amplitude of the thermal ionization signal is shown in Fig. 7.



Fig. 7. The function of the angle of the thermal ionization signal amplitude relative to the angle of maximum combustion pressure
These points are described by a second degree polynomial with a determination coefficient $\mathrm{R}^{2}=0.99$ :

$$
\alpha \_I O N=-0.0303 \cdot\left(\alpha \_P \max \right)^{2}+1.637 \cdot\left(\alpha \_P \max \right)-3.9436
$$

The above function has shown that there is a large correlation between the angles of both signals, which enables the reproduction of the angle of the thermal ionization amplitude based on the angle of maximum combustion pressure. The phase shift of the signals may be related to the local nature of the measurement or to a greater impact of the combustion temperature effect on the thermal ionization signal. Nevertheless, a thermal ionization signal can successfully be used to manage and control the ignition or, more generally, to control the combustion process.

The signals shown are average values from 100 engine cycles, which is too general (too many cycles) for ignition timing control or combustion control. The mean angle of maximum combustion pressure determined by the average angle of incidence of the thermal ionization amplitude (from 5 successive work cycles) indicates an error of \pm 0.25 degrees on the crankshaft. This is an acceptable value for engine control. It is more difficult to analyze the fastchanging analog signal with high variability that is the result of the stochastic nature of the engine. It is necessary to use complex algorithms and to eliminate interference from high-voltage discharges to obtain the desired maximum ionization voltage signal and the angle of its occurrence.

\section{Conclusions}

Analysis of the test results indicates the possibility of using an ionization voltage signal to diagnose the combustion process of a spark ignition engine.

The conducted research and analysis lead to the conclusions that:

1. A partial correlation between the maximum combustion pressure and the ionization voltage has been found. As the maximum combustion pressure increases, the ionization signal voltage increases, but there is no clear dependence.

2. There is a strong relation between the angle of the thermal ionization signal amplitude and the angle of the maximum combustion pressure. This relationship enables the reproduction of the maximum combustion pressure angle from the recorded ionization signal values.

Further research in this field will be conducted with respect to changes in the air excess ratio and the possibility of eliminating the information noise associated with the electric discharge on the spark plug.

\section{Nomenclature}

CI

CNG

DI

HCCI

ION_AV

ION_VOI

Pmax compression ignition compressed natural gas direct injection homogeneous charge compression ignition average value of ionization signal ionization voltage maximum pressure
SI

TDC

U_IONmax

$\alpha \_I O N m a x$

$\alpha \_$Pmax spark ignition top dead center maximum ionization voltage angle of maximum ionization current/voltage angle of maximum pressure 


\section{Bibliography}

[1] WENDEKER, M., Sterowanie wtryskiem w silniku samochodowym. Lubelskie Towarzystwo Naukowe. 1999.

[2] FILIPEK, P.,WENDEKER, M. Opinion of ionization signal to estimating composition of mixture in combustion process about engine SI. Journal of KONES Powertrain and Transport. 2008, 15(3).

[3] BYTTNER, S., HOLMBERG, U. Closed-loop control of EGR using ion currents. Proceedings of the 27th IASTED International Conference modelling, identification and control. 2008, 978-0-88986-711-6.

[4] ERIKSSON, L, NIELSEN, L, GLAVENIUS, M. Closed loop ignition control by ionization current interpretation. SAE Technical Paper. 1997, 970854.

[5] MEHRESH, P., SOUDER, J., FLOWERS, D. et al. Combustion timing in HCCI engines determined by ion-sensor: experimental and kinetic modeling. Proceedings of the Combustion Institute.2005, 2701-2709.

[6] KOWALSKI, D. Analiza nierównomierności pracy silnika o zapłonie samoczynnym z wtryskiem wielofazowym. Rozprawa doktorska. Opole 2014.

\footnotetext{
Łukasz Fiedkiewicz, Eng. - Faculty of Machines and Transport at Poznan University of Technology.

e-mail: Lukasz.Fiedkiewicz@put.poznan.pl
}

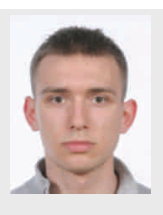

Ireneusz Pielecha, DSc., DEng. - Faculty of Machines and Transport at Poznan University of Technology.

e-mail:Ireneusz.Pielecha@put.poznan.pl
[7] ABHIJIT, A., GEORGE, G., NABER, J. Correlation of air fuel ratio with ionization signal metrics in a multicylinder spark ignited engine. SAE Technical Paper. 2009; 2248, 4562.

[8] ABHIJIT, A., NABER, J. Ionization signal response during combustion knock and comparison to cylinder pressure for SI engines. SAE Technical Paper. 2009; 2159, 25-40.

[9] HELlRING, M., HOLMBERG, U. A comparison of ioncurrent-based algorithms for peak pressure position control. SAE Technical Paper. 2001, 2001-01-1920.

[10] HUNG, D., ZHU, G., DANNE, N., MCKOSKEY, J. Knock detection for a large displacement air-cooled V-twin motorcycle engine using in-cylinder ionization signals. SAE Technical Paper. 2008, 2008-32-0028.

[11] LUNDSTROM, D., SCHAGERBERG, S. Misfire detection for prechamber SI engines using ion sensing and rotational speed measurements. SAE Technical Paper. 2001, 2001-010993.

Prof. Krzysztof Wisłocki, DSc., DEng. - Faculty of Machines and Transport at Poznan University of Technology.

e-mail: Krzysztof.Wistocki@put.poznan.pl 